\title{
EL COLLAR DE ADONIS: CASTILLO SOLÓRZANO, DIEGO DE FRÍAS Y MIGUEL DE BARRIOS EN LA ESTELA DE OVIDIO
}

\author{
ROCÍO JODAR JURADO \\ Universidad de Córdoba \\ 172jojur@uco.es
}

\section{Venus y Adonis en LaS Letras ÁUREaS}

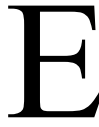

1 mito de Venus y Adonis goza de una amplia trayectoria dentro de nuestro panorama literario. La primera versión se la debemos a Diego Hurtado de Mendoza, quien en 1543 publicó en Venecia su Fábula de Adonis, Hipómenes y Atalanta. El poema está escrito en octavas reales y conjuga en sus versos la naturalidad en la narración con el tono sentencioso y reflexivo propio del tema (Jiménez Bermejo 1989: 71). Le siguen la breve Fábula de Venus y Adonis, de Pedro de Padilla -recogida en el Tesoro de varia poesía (Madrid, 1580) y editada por Labrador Herraiz y DiFranco (Padilla 2008: 63-64)- y el Llanto de Venus en la muerte de Adonis (Segunda parte de las obras de Juan de la Cueva, 1604), de Juan de la Cueva (Cossío 1998a: 177). También de la primera mitad del XVII datan Los fragmentos de Adonis de Soto de Rojas (Granada, 1619), estudiados minuciosamente por Egido (Soto de Rojas 1981), así como la Fábula de Mirra, Adonis y Venus, de Tirso de Molina, recopilada, en 1635, en su Deleitar aprovechando (O1tra 1985). Durante la segunda mitad del Quinientos se registran Venus y Adonis. Fábula trágica de Gabriel Garcés y Gralla (Lisboa, 1596), editada recientemente por Ruiz Pérez (Garcés y Gralla 2015); la Fábula de Venus y Adonis de Juan de Moncayo (Rimas, Zaragoza, 1652), analizada por Giral Viu (2002), Álvarez Amo y Cano Turrión (2015: 126-127); y la homónima de Agustín de Salazar y Torres (Cítara de Apolo, Madrid, 1694), editada por Tenorio (2010: 473-516).

Sin embargo, la primera subversión burlesca salió de la pluma de Alonso de Castillo Solórzano, cuya Fábula de Adonis, incluida en la primera parte de sus Donaires del Parnaso (Madrid, 1624), abordamos en este trabajo. El texto apenas 
ha sido estudiado, lo cual no debe sorprendernos pues, como apunta Giorgi (2014: 257), «la producción literaria del [vallisoletano] [...] ha sido objeto de muchas críticas por sus límites estilísticos [y] falta de originalidad». De hecho, no se trata de una idea del todo nueva, pues hace décadas que Cossío (1998b: 268) denunció que los Donaires «no han sido estimados con la atención que merecen».

Así las cosas, las breves referencias en torno a la Fábula de Adonis se cifran apenas en el repertorio de Cossío (1998b: 317-321) y en la edición de López Gutiérrez (Castillo Solórzano 2003: 171-176), si bien es cierto que Bonilla Cerezo (2006: 67-73) ha firmado un concienzudo estudio de los Donaires y sus ecos gongorinos. Asimismo, no podemos obviar los asedios de Jauralde Pou (1979), Montero Reguera (1998) y Rodríguez Mansilla (2008) a los versos del autor del Trapa$z a$. Cerramos esta breve reseña con el artículo sobre las dos «primeras ediciones» de los Donaires que Paolo Pintacuda (2017) nos regala en este mismo volumen.

No obstante, el éxito del epilio ${ }^{1}$ del vallisoletano debió ser más que notable, pues inspiró otras dos fábulas burlescas del Seiscientos: la Fábula de Adonis, de Diego de Frías, y la homónima del capitán Miguel de Barrios. La Fábula de Adonis de Frías fue conocida en la época gracias a su inclusión en las Poesías varias de ingenios españoles (1654) y, dieciséis años más tarde, en las Delicias de Apolo (1670), de José Alfay. Asimismo, el romance se copió en al menos tres manuscritos de los que da noticia Cossío (1998b: 320): los signados como 3794 (ff. 209r-212v), 3811 (ff. 39r-42v) y 3985 (ff. 168r-172v), todos ellos en la Biblioteca Nacional de España. Dichos testimonios transmiten una versión distinta de la recopilada por Alfay, con no pocas variantes, supresiones y alteraciones del orden de los cuartetes. Citaremos el texto a partir de la versión impresa, si bien haremos mención a los manuscritos cuando resulte pertinente.

En cuanto a Barrios, se conservan dos versiones de su texto, ambas escritas en redondillas. La primera de ellas -en adelante $A$ - apareció en la Flor de Apolo de 1665; la segunda -en adelante $B-$-, en El coro de las musas (1672), objeto de la tesis de García Gavilán (2002). Las variantes son de calado y afectan a todo el relato, por lo que en realidad nos encontramos ante un caso de reescritura. En esta oportunidad, aludiremos a ambas indicando siempre la respectiva versión $(A$ o $B)$. Citaremos a partir de la edición de Sedeño Rodríguez (Barrios 1996).

Las semejanzas entre este trébol de fábulas adónicas son tan obvias que incluso hay quien ha acusado a Frías y Barrios de plagiarios (Jauralde Pou 1979: 753). Más allá de lo gratuito de tales pullas -que niegan el valor literario de estas composiciones y eluden por completo el concepto de imitatio-, es evidente que los

\footnotetext{
1 A zaga de Ponce Cárdenas (2001: 63) y Perutelli (2000: 49-82), usamos los términos «fábula mitológica» y «epilio» como sinónimos, distinguiendo únicamente entre epilios serios y burlescos.
} 
poemas forman parte de un extenso collar literario que comenzó a forjarse desde la antigüedad clásica.

\section{Castillo Solórzano y la ReESCRITURA DE UN Mito}

La trama del mito que nos ocupa se antoja bastante sencilla. En el libro X de las Metamorfosis (Ovidio 1998: 318-324), a continuación de la Fábula de Mirra, se nos narra el nacimiento de Adonis a partir de la corteza de un árbol, sus primeros años y su posterior encuentro con Venus, quien lo alecciona contra los animales que lucen armas naturales, amén de referirle la Fábula de Atalanta. A pesar de ello, Adonis muere a resultas de su combate con un jabalí que lo hiere en la ingle. Finalmente, Venus hace que broten anémonas de su sangre. Castillo imprime a sus versos un cariz paródico que lo aleja de la fuente ovidiana, por lo que se antoja necesario analizar el texto en cuestión para comprender cómo la parodia y la burla inciden sobre la materia poética, y cómo años después Frías y Barrios reciclaron buena parte de sus hallazgos.

El romance se abre con la consabida invocación burlesca (vv. 1-28), dirigida al dios Apolo. En esta obertura el poeta alude con tono chancero a los amores de Febo y Calíope, madre de Orfeo, y retrata al coro de las musas como «cuñadas» del Sol. No se trata de una referencia aislada en la obra del tordesillano, pues la reiteró en el íncipit de la Fábula de Acteón, donde abundaría en la lascivia de su protagonista: «pienso cantar, si anima mi torrente / la musa más sufrida, / que Apolo, en su serrallo parnaseo, / de socarrón olvida / para tener con otra su bureo» (vv. 4-8) (Castillo 2003: 304). El apóstrofe termina presagiando el «trágico» desenlace mediante el uso de la prolepsis: «cuente el trágico suceso / del joven que murió en flor, / y flor le gozan los huertos» (vv. 26-28). El uso de la antanaclasis a propósito del término «flor» le permite al autor desplegar un rosario de juegos de palabras. Dicho empleo se registra asimismo en las fábulas de Frías (vv. 365-368) y Barrios ( $A$, vv. 197-200).

Si bien Barrios suprime cualquier tipo de invocación en ambas versiones de su obra, Frías sigue de cerca el modelo de Castillo e introduce los hechos con una breve dedicatoria, dirigida en esta ocasión a un «tú» indeterminado que hace las veces de destinatario: «iOh, dulce honor de mi pluma!, / tú, a quien dedico estas letras, / escucha de avena torpe / numerosas diferencias» (vv. 1-4). La alusión a la avena inscribe al texto de Frías dentro de los géneros menores. Si bien la fuente clásica directa es Virgilio, en el ámbito hispánico esta acepción de la «avena» («instrumento músico. Lo mismo que flauta», Aut.) se documenta ya en el Arcipreste de Hita y se registraría algo más tarde en la Égloga II de Garcilaso, en $L a$ Vega del Parnaso de Lope y en el «Prólogo» al Quijote de Cervantes, alternando 
con la «zampoña» en el Polifemo de Góngora (Bustos 1986: 137-138). Además, al cotejar el impreso con los manuscritos, observamos cómo los testimonios que no llegaron a los tórculos eliminan dos cuartetes esenciales a la hora de interpretar esta referencia, pues en ellos se hace mención de otros instrumentos -más o menos rudos-con los que Frías compara jocosamente a la avena: la gaita zamorana, el castrapuercos y el silbato.

Por tanto, aunque mantiene la dedicatoria, remplaza el destinatario mitológico (Apolo) por un «túu de carne y hueso al que brinda una reflexión de signo metapoético acerca del cariz chocarrero de su poema, al socaire del que nos ofreció Góngora en el Polifemo cuando remitía a la zampoña, la cítara y el clarín (Caldera 1967: 228).

Tras el íncipit, Castillo Solórzano dibuja la típica cronografía áurea: «Ya los fogosos caballos / del flamígero cochero / la carroza celestial / en el cenit habían puesto» (vv. 29-32). Febo es representado aquí -según la costumbre- como un cochero, profesión objeto de escarnio por numerosos ingenios del Siglo de Oro. Bastará citar los vv. 91-95 de Las visiones de la muerte, de Calderón (1983: 387); el v. 10 de El sacristán fariseo, entremés atribuido asimismo al dramaturgo madrileño (Buezo 1990: 104); y el Famoso entremés de Getafe, de Antonio Hurtado de Mendoza. No en balde, el propio Castillo Solórzano (2003: 392) pondría en solfa a este gremio, añadiendo a sus vicios el del chismorreo (vv. 121-128), en su romance «De Apolo a Dafne».

Barrios opta por eliminar este pasaje, mientras que Frías, más apegado al texto del tordesillano, no solo conserva la referencia temporal, sino que la «castellaniza» al identificar a los cuartagos de Apolo con Babieca, el caballo del Cid (vv. 49-56). Es llamativo, además, cómo en la versión impresa de este romance la cronografía no aparece tras la invocación - tal y como ocurría en los manuscritos-, sino que se inserta tras la localización espacial del encuentro amoroso. La alteración en la dispositio puede obedecer a varias causas, entre las que no deberíamos desechar una posible reescritura del texto, o un hipotético desliz del cajista transmitido desde las Poesías varias a las Delicias de Apolo. Sea como fuere, las concomitancias son más que notables. Frías llega incluso a adoptar el léxico de Castillo, más precisamente los adjetivos «fogosos» -al lado del sustantivo «caballos»-y «flamígero»-aquí con el sustantivo «cochero»-, que aplica luego a la «carrera» (v. 50) y los «cuartagos» (v. 49). Lo mismo vale para el «filo» (v. 53), que especifica esta vez con un sustantivo, en lugar del complemento preposicional al que había acudido el pucelano. La traslación de adjetivos («fogosos»-«caballo» / «flamígera»-«carrera») orilla de nuevo las referencias directas a Febo, a la par que subraya la relación con el texto modelo.

La narración propiamente dicha comienza con la presentación de los personajes, punto de partida en las Metamorfosis y en la mayor parte de los epilios serios. 
El autor de Las harpias de Madrid describe sucintamente a Venus. Alude a Accidalia como madre de Cupido e incide en su nacimiento con visos deterministas («tan reconocida / a aquel origen primero, / que de lo leve y lascivo / ella vino a ser compuesto», vv. 45-48). Frías y Barrios se decantan en cambio por la amplificatio. Ambos añaden pinceladas clásicas en torno a la diosa; remiten a su hijo, a su nacimiento y a su papel en la guerra de Troya (Frías, vv. 57-72; Barrios, $A$, vv. 5-16). Coinciden asimismo el tratamiento de Venus, a la que ensalzan y denigran a partes iguales. Llamativo es el uso que Barrios hace del calambur («más que otras hermosa es pera»; $A$, v. 8). Este tropo es muy común en el autor sefardita y se registra en varias ocasiones a lo largo del poema: «Bizarra a todo galán / daba el solimán de amor, / si de la hermosura flor, / de la luz del sol-imán» ( $A$, vv. 21-24), «mostrando en-ojos al sol» ( $A$, v. 96), «poniéndose el campo enaguas» $(A$, v. 110$)$, «previno herirlo a-bocados» $(A$, v. $271 ; \mathrm{B}, \mathrm{v} .299)$, «que la flor que trae azar, / suele en muchos ser de-lirio» ( $A$, vv. 371-372; $B$, vv. 407-408).

Tras la descriptio de Accidalia, Castillo y Frías prestan atención al mancebito objeto de sus amores. Barrios inserta entre ambas descripciones cinco redondillas en el caso de $A$, y un total de once en $B$, en las que nos relata la llegada de Venus al arroyo donde se reunirá con Adonis para, seguidamente, abordar el retrato del hermoso muchacho. El pasaje inserto por Barrios resulta, en cualquier caso, bastante anecdótico.

Castillo Solórzano define a Adonis como el fruto de los amores incestuosos de Mirra y Cinara (vv. 53-60), al tiempo que pondera su belleza y gallardía; mas lo hace de forma general, sin aludir en exceso a su físico. Frías y Barrios, por su parte, caracterizan a Adonis como un galán imberbe y poco agraciado, a imagen de la jocosa prosopografía que Góngora había trazado de Píramo (vv. 101-120) en su Fábula de Píramo y Tisbe (Góngora 2000: 502-503). A diferencia de Castillo, Frías sí que hace hincapié en la vestimenta del protagonista. Compara a Adonis con un petimetre ${ }^{2}$ y destaca su bozo, con atributos de flor (vv. 77-88), metáfora epitalámica ligada desde antiguo a la virilidad (o falta de la misma) del adolescente (Ponce Cárdenas 2009: 144); verbigracia en los vv. 279-280 de la Fábula de Polifemo: «flores su bozo es, cuyos colores, / como duerme la luz, niegan las flores» (Góngora 2000: 345). Frías parodia el tópico al comparar el bigote de Adonis con el azafrán (v. 79), tachándolo, pues, de pelirrojo, un color denostado durante el Siglo de Oro. No en vano el propio Castillo había afilado su pluma contra los pelirrojos en su Fábula de Pan y Siringa, donde se cebó con un fauno bermejo:

$\overline{2}$ En los mss. 3794 y 3985, Frías se complace todavía más en la pintura del mancebo, a lo largo de dos cuartetes nuevamente omitidos en la versión impresa (el mss. 3811, por su parte, no reproduce el primero de estos cuartetes): «La tez era semiblanca / de claveles y azucenas, / si ellos aquí vencedores, / aquí vencedoras ellas. / Las pantorrillas y el peto / pelotudo eran a prueba / de mosquete, que a la burra / no empece la boca negra». 
«El color del rostro y cuerpo / es tan bermejo que dudo / que del licor bacanal / jamás le han hallado ayuno» (vv. 193-196) (Castillo 2003: 377). Volviendo al texto de Frías, el neologismo «mostachil» (v. 79), despectivo a las claras, refuerza el carácter burlesco de los versos. No saldrá mejor parada la nariz de Adonis, «aguzada y aguileña» (v. 82), que no puede más que recordarnos al autorretrato que Góngora se dedicó en su romance «Hanme dicho hermanas»: «digo su aguileña / filomocosía / (ya que no pintada, / al menos, escrita)» (vv. 9-12) (Góngora 2000: 86).

Barrios desarrolla una descriptio viri mucho más atinada, pues le asigna a cada uno de los tópicos un oportuno contrapunto burlesco que rebaja la imagen del mancebo. El montillano se recrea en un galán cejijunto $(A, \mathrm{v} .152)$, inclinado a la burla ( $A$, v. 156) y, como en el caso de Frías, también imberbe ( $A$, vv. 162-164). Además apela al olfato, ya que al muchacho le huele el aliento («el hablar siempre atufado»; $A$, v. 140). Nótese que este verso podría sugerir una velada alusión al lenguaje culto, el mismo defecto que Castillo Solórzano había atribuido a Acis en los vv. 257-264 de su Fábula de Polifemo a la Academia de Madrid (Castillo 2003: 406). Asimismo, «atufado» también podría relacionarse con el tono indecente y obsceno del poema, es decir, con el genus turpe que tanto protagonismo cobró en la retórica gongorina ${ }^{3}$. Nada queda, pues, de la vestimenta de Adonis, sin duda el principal hallazgo del texto de Frías.

Tras la pintura de los personajes, Castillo alude al locus amoenus en el que se sitúa la acción. Por medio de la metáfora, el tordesillano presenta un prado con un dosel natural «sin goteras» (v. 83) en el que se distinguen el canto de las aves, el repiqueteo del «órgano de un río» (v. 87) y el «son que en las hojas hace / un vientecillo travieso» (vv. 89-90). Un cuadro natural que recuerda lejanamente a los vv. 373-376 de la Fábula de Polifemo a la Academia de Madrid: «dosel opaco de una yedra hojosa / yace, donde con pasos de garganta / se miran de las aves dos capillas, / que en su alabanza cantan seguidillas» (Castillo 2003: 410). Tampoco sorprende la alusión a las diferentes flores que lo adornan, tejiendo una alfombra para los amantes; una imagen que Castillo (2003: 352) había esbozado igualmente en la Fábula de Marte y Venus: «Todos bajan a la tierra, / y sus tapetes compone / Flora, su copia vertiendo / con diversidad de flores» (vv. 117-120).

\footnotetext{
A propósito de la turpitudo, como apunta Luján Atienza (2006: 57), «la verdadera subversión gongorina no estriba simplemente en nombrar lo prohibido y regocijarse en ello [...], sino en establecer entre la seriedad y la burla, entre lo importante y lo chocarrero, una frontera inexistente». Tanto Castillo como sus epígonos se aprovechan de las innovaciones del cordobés, pues todos incluyen en sus textos imponentes cronografías, reflexiones morales y vistosas descripciones paisajísticas junto a alusiones obscenas, chistes chocarreros y personajes de baja ralea. El resultado de esta mezcla es la creación de mundos poliédricos y deliberadamente ambiguos, en los que en ocasiones es difícil diferenciar la voz narrativa del autor. Claro ejemplo son los versos finales del poema de Barrios, en los que se pone en cuarentena la veracidad de los hechos y, por tanto, la fiabilidad de la voz narrativa.
} 
Este pasaje halla su correlato en los vv. 5-48 del impreso del poema de Frías, si bien en los manuscritos se inserta tras la descripción de Adonis, como en el epilio de Castillo. Cabría, pues, pensar que los manuscritos siguen más de cerca el texto del tordesillano.

Dejando a un lado estas cuestiones, no es justo estimar la obra de Frías como un plagio de la fábula de los Donaires del Parnaso, pues en ella da entrada a una vistosa batalla floral. Como si de una reyerta fronteriza se tratara, las retamas son aquí «moriscas» (v. 27) y las azucenas «católicas» (v. 28); el clavel ostenta el rango de «capitán de la floresta» (v. 30) y, «bañado en sangre olorosa» (v. 31), sobresale por su incansable valor; la rosa ondea «candidísimas banderas» (v. 36); y la mosqueta y el junquillo se encargan de disparar «mosquetazos» (v. 38) y «flechas» (v. 40). Colores y fragancias inundan unos versos llenos de castrense sensorialidad. Ambos trazos, aliados con el guiño al romancero de frontera, distancian esta escaramuza de la mediocre y desganada enumeración floral del epilio de Castillo.

Barrios no parece interesado en el paisaje, pues aboceta el locus amoenus tras la descripción de la isla Accidalia, sede que no coincide con las que asomaban en los textos que pudo tomar como falsilla. Mantiene, no obstante, algunas de las claves del texto de Castillo Solórzano. A saber: la presencia del arroyo que mitiga la sed de la diosa ( $A$, vv. 105-106; $B$, vv. 101-102), la presencia de las flores $(A$, v. $112 ; B$, v. 108$)$ o el canto de las aves $(A$, v. $117 ; B$, v. 109). Eso sí, dichos elementos bien pudo haberlos tomado de la tradición clásica o de la medieval (Curtius 1976: 280; López Bueno 2005: 391-399).

El encuentro amoroso apenas es descrito por Castillo Solórzano, si bien abunda en la imagen del voyeur que encarna Cupido, del todo complacido ante la escena del amplexo (vv. 129-132). Esta pasión culminará con un beso de atrevidas resonancias gongorinas: «Por vasijas de coral / se trocaban los alientos, / animándose a sí mismo / cada cual con el ajeno» (vv. 133-136). Este cuartete halla su reflejo en los vv. 93-96 de la fábula de Frías: «por búcaros de clavel, / bebían los dos a medias / palabras tan amorosas / que se quebraban de tiernas». Sin embargo, se percibe una clara alteración al introducir un elemento sonoro, la palabra, en sustitución del aliento, lo que intensifica la carga pasional del idilio, no solo presenciado, sino también escuchado por el lector. Barrios elude toda referencia al beso, acentuando en cambio la lujuria de la diosa, a la que burlonamente compara con una monja recoleta, una de las órdenes femeninas de la época: «Ericina, muy inquieta, / los ojos al joven alza, / porque, aunque estaba descalza, / era poco recoleta» ( $A$, vv. 193-196). Asimismo, alude al coito de los jóvenes y a la pérdida de la virginidad de la protagonista: «Abrazola con lealtad / el gallardo cazador, / que, por conocer su flor, / murió en la flor de su edad» (A, vv. 197-200). A pesar de que el sefardita se desvía aquí del texto de Castillo y de la carga burlesca que este había impreso sobre su cuartete, esta versión discurre más próxima al texto 
ovidiano que el resto, pues en las Metamorfosis nunca se describe el beso, sino que tan solo se alude de pasada a los basia (Ovidio 1998: 31w9).

El abrazo de los novios despierta los celos de Marte, que se duele en primera persona y arremete contra ellos de inmediato. He aquí uno de los lances más novedosos del poema del vallisoletano. Tras un buen número de imágenes de cuño emblemático acerca de los celos, Marte, con tono socarrón, clama venganza (vv. 165184). A lo largo de este soliloquio se aprecian algunas de las características propias de Castillo, tales como el uso de coloquialismos («juro a mí», v. 165), refranes («en cas de un esgrimidor / nunca sobraron talegos», vv. 175-176) y largos periodos oracionales más genuinos de la prosa que del verso. Tales recursos se registran también en Frías, que va tras las huellas del pucelano (vv. 105-128). Frías recicla la imagen emblemática de los celos como culebras (v. 106), el juramento del dios (v. 110) y los refranes populares («en casa de esgrimidor / nunca se hallaron gavetas», vv. 115-116). No obstante, introduce ciertas notas de originalidad respecto a su modelo, como la paronomasia de los vv. 123-124 («sirviendo mi astroso labio / de astrolabio a esta ciencia») o el guiño a los trabajos de Hércules en los vv. 125-128.

Por su parte, Barrios suma las credenciales "bélicas" del diosecillo: «Yo soy aquel rey de espadas / que, para el gallina o gallo, / que así triunfa de caballo, / inventó las cabezadas» ( $A$, vv. 253-256). La fuente de estos versos se localiza en el segundo monólogo de Marte de la fábula de Castillo (vv. 309-340), del que nos ocuparemos más adelante. Se trata, a fin de cuentas, de una fusión de ambos pasajes.

Ericina recomienda enseguida a Adonis que se mantenga lejos de los jabalíes y, sin esperar la réplica, desaparece. Lo inédito es que Castillo sustituye la voz «jabalí» por otras más coloquiales, potenciando así el juego de palabras con «puerco»: «que no te halles, si eres limpio, / jamás en caza de puercos; / que con la cochinería / estoy enojada y temo / de aqueste puerco ejercicio / un asqueroso suceso» (vv. 207-212). La cacería es aquí un «puerco ejercicio» por dos motivos: 1) tiene como objetivo abatir jabalíes o cerdos; y 2) se trata de una actividad vinculada a la suciedad y, por extensión, a los judíos -llamados despectivamente «marranos»-, como deja entrever la nota antisemita del v. 207. El chiste es suprimido por Frías, si bien Barrios lo rescató en $A$ (vv. 295-296) y en $B$ (vv. 319-320): «si eres limpio, que jamás / andes de puercos a caza». El hecho de que el capitán montillano lo mantenga en sus dos versiones resulta más llamativo si cabe al valorar que era judío. Barrios sigue a plana y renglón el modelo de Castillo, al margen de su propio credo, que sacrificó esta vez en el altar de las burlas.

Tras la marcha de Venus, asistimos a la transformación de Marte. La fábula se convierte así en un mito con doble metamorfosis, de manera que en los vv. 229272 Castillo perfila la transmutación gracias a la metáfora. El autor nos presenta a un dios vestido con «capote de pellejos» (v. 234), «peliblando» (v. 235) y «pelitieso» (v. 236), epítetos que emulan a los compuestos por composición, derivación 
o parasíntesis («pelinegra», «pelirrubia», «pelijudas») tan frecuentes en Quevedo (Alarcos García 1995: 14-26). Esta imagen se registra también en Frías, quien sustituyó el capote por una prenda más de andar por casa: el sayo (vv. 165-168). Después del pelaje, le toca el turno a la boca, poetizada por el vallisoletano como un «cañón de dos bocas» (v. 245). No sorprende por ello que Frías hiciera suya tan bizarra imagen: «por arcabuz de dos bocas / lumbre emula, fuego alienta» (vv. 169-170).

Finalmente, sobresale la aguda comparación del jabalí con dos casas nobiliarias: «Salió de una gruta escura, / por dar color al enredo, / don Verraco de Cerdán, / don Marrano de Sedeño» (vv. 265-268). Ocurrencia que disfrutó de cierto aplauso entre los epígonos de Castillo, ya que la adoptaron tanto Frías (vv. 181-184) como Barrios ( $A$, vv. 313-316; $B$, vv. 337-340) ${ }^{4}$. Con todo, el montillano simplificó lo suyo el pasaje, ya que, más que la transformación del dios, nos muestra a un Marte convertido ya en jabalí. Se trata de una técnica muy habitual en este tipo de epilios; incluidos los de largo aliento, como el Adone de Marino, donde «las transformaciones serán siempre un mero topos impuesto por la tradición» (Pozzi 1976: 51). Otros ejemplos dentro de la producción del tordesillano se registran en los vv. 192-195 de la Fábula de Acteón (Castillo 2003: 310-311) y en los vv. 319320 de la Fábula de Pan y Siringa (Castillo 2003: 381).

Por lo que toca al asesinato de Adonis, asoman en este pasaje claras diferencias respecto a las Metamorfosis. Si en el libro ovidiano Adonis sufría una herida en la ingle, Castillo, exprimiendo todas las claves burlescas, acude al eufemismo para sugerir que el protagonista recibió un colmilludo embate por el ano: «Diole cuatro navajadas, / el por dónde no os lo cuento, / bastantes a dar el alma / por el menor agujero» (vv. 297-300). Frías y Barrios se pliegan al texto latino, lo que evidencia que juzgaron de mal gusto -o excesivo- el chiste sodomita.

No estriba aquí la única diferencia entre Castillo, Frías y Barrios, pues, a renglón seguido de la pugna entre Adonis y Marte, el tordesillano reservó otro monólogo para el dios de la guerra. Además de revelarle su identidad a la víctima, Marte hace gala de su destreza en combate (vv. 313-328). Diego de Frías sigue la falsilla de los Donaires del Parnaso en los vv. 217-232, si bien Barrios, como hemos dicho, lo elimina por mor de la fusión con el anterior soliloquio del belicoso jabalí.

La huida de Marte marca un punto de inflexión en la fábula de Barrios. A partir de este momento, se simplifican notablemente los hechos. Castillo y Frías, por contra, se muestran más precisos: así, junto a la consabida anécdota del rosal, incorporan un monólogo chancero de Adonis a las puertas de la muerte, escoltado por un planto de Venus, también en primera persona, y un desfile de faunos y ninfas ${ }^{5}$

\footnotetext{
4 A propósito de otras semejanzas entre las respectivas obras de Castillo Solórzano, Francisco Bernardo de Quirós y Miguel de Barrios, véase Bonilla Cerezo (2009).

5 El tópico se documentaba ya en Diego Hurtado de Mendoza, quien, en su Fábula de Adonis,
} 
Tanto Castillo como Diego de Frías rematan sus textos con un llamativo epitafio en el haber de un par de faunos. El pucelano subraya su socarronería con neologismos («faunismo», v. 498), expresiones coloquiales («andar a la flor del berro», v. 504) y un eufemismo sexual («y al fin, le mató el cochino / por la parte que pecó», vv. 509-511). Frías se muestra mucho más contenido, y si bien mantiene la alusión a la flor del berro, carga menos las tintas cómicas. A guisa de corolario, desliza un apóstrofe en segunda persona que parece alertar al lector. Se trata, en definitiva, de un falso didactismo que descansa sobre los pilares de la ironía. Por su parte, Barrios sustituye dicho epitafio por una reflexión metanarrativa acerca de la veracidad de lo ocurrido (Barrios, $A$, vv. 405-412). El «locutor burlesco» (Arellano 2003: 27-30) no precisa en qué flor se transformó Adonis, pero se vale de la paronomasia («lirio-delirio») para identificar su desgracia con el desenfreno sexual. Comenta, en último término, los hechos y ofrece su versión del asunto al sostener que se metamorfoseó, al igual que en los casos anteriores, en la «flor del berro» (v. 411), a resultas de su holgazanería y no de su amor por la diosa.

Ofrecemos a continuación la dispositio de los argumentos e indicamos en negrita los cambios:

\begin{tabular}{|l|l|l|l|}
\hline \multicolumn{1}{|c|}{$\begin{array}{c}\text { Fábula de Adonis } \\
\text { de Castillo Solórzano } \\
\text { (romance) }\end{array}$} & \multicolumn{1}{|c|}{$\begin{array}{c}\text { Fábula de Adonis } \\
\text { de Diego de Frías } \\
\text { (romance) }\end{array}$} & $\begin{array}{c}\text { Fábula de Adonis } \\
\text { de Miguel de Barrios, } A . \\
\text { (redondillas) }\end{array}$ & $\begin{array}{c}\text { Fábula de Adonis } \\
\text { de Miguel de Barrios, } B .\end{array}$ \\
(redondillas)
\end{tabular}

Hipómenes y Atalanta, no solo incluye un desfile mitológico, sino que entre los asistentes cita al dios Momo y al mismísimo Júpiter. Sobre esta fábula, véase Roses Lozano (1998). 


\begin{tabular}{|c|c|c|c|}
\hline & & $\begin{array}{l}\text { vv. 101-120: Venus llega al } \\
\text { prado. }\end{array}$ & $\begin{array}{l}\text { vv. } 97-140 \text { : Venus llega al } \\
\text { prado. }\end{array}$ \\
\hline $\begin{array}{l}\text { vv. 53-80: Presentación de } \\
\text { Adonis. }\end{array}$ & $\begin{array}{l}\text { vv. } 73-88 \text { : Descriptio viri de } \\
\text { Adonis. }\end{array}$ & $\begin{array}{l}\text { vv. 121-176: Descriptio viri } \\
\text { burlesca de Adonis. }\end{array}$ & $\begin{array}{l}\text { vv. 141-192: Descriptio viri } \\
\text { burlesca de Adonis. }\end{array}$ \\
\hline $\begin{array}{l}\text { vv. 81-124: Locus amoemus y } \\
\text { naturaleza musical. }\end{array}$ & & & \\
\hline $\begin{array}{l}\text { vv. 125-140: Encuentro } \\
\text { amoroso. }\end{array}$ & $\begin{array}{l}\text { vv. 89-100: Encuentro amoro- } \\
\text { so. Los vv. } 97-100 \text { aluden a } \\
\text { la sede donde se desarrolla } \\
\text { el encuentro. En los mss. se } \\
\text { detalla junto a la descripción } \\
\text { del locus, como en la fábula } \\
\text { de Castillo Solórzano. }\end{array}$ & vv. 177-208: Encuentro amoroso. & $\begin{array}{l}\text { vv. 193-216: Encuentro amo- } \\
\text { roso. }\end{array}$ \\
\hline $\begin{array}{l}\text { vv. 141-192: Presentación de } \\
\text { Marte. }\end{array}$ & $\begin{array}{l}\text { vv. 101-136: Presentación de } \\
\text { Marte. }\end{array}$ & $\begin{array}{l}\text { vv. 209-280: Presentación de } \\
\text { Marte. }\end{array}$ & $\begin{array}{l}\text { vv. 217-304: Presentación } \\
\text { de Marte. }\end{array}$ \\
\hline vv. 193-228: Salida de Venus. & vv. 137-164: Salida de Venus. & vv. 281-304: Salida de Venus. & vv. 305-328: Salida de Venus. \\
\hline $\begin{array}{l}\text { vv. 229-264: Transformación } \\
\text { de Marte en jabalí. }\end{array}$ & $\begin{array}{l}\text { vv. 165-184: Transformación } \\
\text { de Marte en jabalí. }\end{array}$ & $\begin{array}{l}\text { vv. 305-320: Transformación de } \\
\text { Marte en jabalí. }\end{array}$ & $\begin{array}{l}\text { vv. 329-344: Transformación } \\
\text { de Marte en jabalí. }\end{array}$ \\
\hline $\begin{array}{l}\text { vv. 265-348: Lucha entre Marte } \\
\text { y Adonis. Monólogo del dios } \\
\text { de la guerra. }\end{array}$ & $\begin{array}{l}\text { vv. 185-240: Lucha entre Marte } \\
\text { y Adonis. Monólogo del dios } \\
\text { de la guerra. }\end{array}$ & $\begin{array}{l}\text { vv. 321-350: Lucha entre Marte } \\
\text { y Adonis. Huida del dios de } \\
\text { la guerra. }\end{array}$ & $\begin{array}{l}\text { vv. } 345 \text { - 376: Lucha entre } \\
\text { Marte y Adonis. Huida del } \\
\text { dios de la guerra. }\end{array}$ \\
\hline $\begin{array}{l}\text { vv. } 350-372 \text { : Regreso de Venus } \\
\text { a causa del lamento de Adonis. } \\
\text { Episodio del rosal. }\end{array}$ & $\begin{array}{l}\text { vv. 241-260: Regreso de Venus } \\
\text { a causa del lamento de Adonis. } \\
\text { Episodio del rosal. }\end{array}$ & $\begin{array}{l}\text { vv. 353-364: Regreso de Venus } \\
\text { a causa del lamento de Adonis. } \\
\text { Episodio del rosal. }\end{array}$ & $\begin{array}{l}\text { vv. 377-388: Regreso de Venus } \\
\text { a causa del lamento de Adonis. } \\
\text { Episodio del rosal. }\end{array}$ \\
\hline $\begin{array}{l}\text { vv. 374-408: Últimas palabras } \\
\text { de Adonis. }\end{array}$ & $\begin{array}{l}\text { vv. 261-289: Últimas palabras } \\
\text { de Adonis. }\end{array}$ & & \\
\hline $\begin{array}{l}\text { vv. 375-448: Lamento de } \\
\text { Venus. }\end{array}$ & $\begin{array}{l}\text { vv. 290-296: Duelo de Venus } \\
\text { (sin monólogo). }\end{array}$ & & \\
\hline $\begin{array}{l}\text { vv. 449-500: Llegada de las } \\
\text { dríadas y los faunos. Discurso } \\
\text { de Venus. Metamorfosis de } \\
\text { Adonis. }\end{array}$ & $\begin{array}{l}\text { vv. 297-364: Llegada de las } \\
\text { dríadas y los faunos. Discurso } \\
\text { de Venus. Metamorfosis de } \\
\text { Adonis. }\end{array}$ & $\begin{array}{l}\text { vv. 353-372: Metamorfosis de } \\
\text { Adonis. }\end{array}$ & $\begin{array}{l}\text { vv. 389-408: Metamorfosis } \\
\text { de Adonis. }\end{array}$ \\
\hline 501-510: Epitafio. & vv. 365-368: Epitafio. & $\begin{array}{l}\text { vv. } 373-376 \text { : Comentario final } \\
\text { del sujeto lírico. }\end{array}$ & $\begin{array}{l}\text { vv. 409-412: Comentario final } \\
\text { del sujeto lírico. }\end{array}$ \\
\hline
\end{tabular}

De todo lo dicho, se pueden extraer algunas conclusiones que arrojan luz sobre el origen y la filiación de los textos en liza, sus relaciones intertextuales y su mayor o menor categoría: 
1. Ni Frías ni Barrios plagiaron stricto sensu el poema de Castillo Solórzano. Nos encontramos más bien ante sendos ejercicios de reescritura en los que cada autor amplifica o reduce el mito en pos de sus intereses.

2. Frías se muestra más apegado a la fábula de Castillo Solórzano. Empero, reelabora numerosos pasajes, algunos tan felices como la batalla floral del íncipit. Asimismo, se apoya a menudo en magisterio de Ovidio y presta mayor interés a la descripción de los personajes. En cuanto a la lengua, frente a los largos periodos oracionales de Castillo, apuesta por una menor complejidad que cristaliza en cláusulas que no rebasan por lo general las fronteras de un cuartete. No obstante, recicla varias agudezas léxicas y los originales monólogos de Marte y su metamorfosis en jabalí.

3. Barrios, en sus dos versiones, se distancia de la obra de Castillo, amplificando más de un episodio y simplificando otros. Se decanta además por la redondilla en lugar del romance. El montillano acostumbra a abrazar la minutio, hasta el límite de hibridar el par de monólogos de Marte, reducidos a uno en su epilio. Finalmente, destacan los incisos del locutor, que reemplazan el epitafio de la fábula de Castillo Solórzano.

4. Las diferentes versiones de la obra de Frías parecen indicar que nos careamos con un original en movimiento. Una primera familia de textos, la de los manuscritos, descendería de una primera redacción $(\mathrm{Ol})$, cuya fecha desconocemos, muy apegada a la dispositio del epilio del tordesillano. Posteriormente, $\mathrm{Ol}$ fue objeto de -como mínimo- una rescritura $(\mathrm{O} 2)$, de la que derivan tanto la versión impresa compilada en las Poesías varias (1654) como la de las Delicias de Apolo (1670), que, a su vez, suprime algunos cuartetes y presenta alteraciones en la diégesis, amén de las variantes que recogemos a continuación:

\begin{tabular}{|l|l|l|l|}
\hline \multicolumn{1}{|c|}{ Versión impresa } & \multicolumn{1}{|c|}{ Mss. 3797 } & \multicolumn{1}{c|}{ Mss. 3811 } & \multicolumn{1}{c|}{ Mss. 3985 } \\
\hline $\begin{array}{l}\text { «fogosos pasado habían / } \\
\text { del reventón de la cuesta»; } \\
\text { vv. } 51-52\end{array}$ & $\begin{array}{l}\text { «fogosos pasado habían / el } \\
\text { reventón de la cuesta». }\end{array}$ & $\begin{array}{l}\text { «fogosos pasado habían / el } \\
\text { reventón de la cuesta». }\end{array}$ & $\begin{array}{l}\text { «fogosos pasado habían / el } \\
\text { reventón de la cuesta». }\end{array}$ \\
\hline $\begin{array}{l}\text { «Venus, deidad bandolera»; } \\
\text { v. } 58 .\end{array}$ & «Venus, deidad saetera». & «Venus, deidad saetera». & «Venus, deidad saetera». \\
\hline $\begin{array}{l}\text { «de Troya la buena pieza»; } \\
\text { v. 72. }\end{array}$ & «de Troya la buena pesca». & «de Troya la buena pesca». & «de Troya la buena pesca». \\
\hline $\begin{array}{l}\text { «el jubón a la irlandesa»; } \\
\text { v. } 86 .\end{array}$ & «el jubón a la holandesa». & «el jubón a la holandesa». & «el jubón a la irlandesa». \\
\hline $\begin{array}{l}\text { «vuelto el carro en carabela»; } \\
\text { v. } 134 .\end{array}$ & «vuelto el coche en carabela». & «vuelto el coche en carabela». & «vuelto el coche en carabela». \\
\hline
\end{tabular}




\begin{tabular}{|l|l|l|l|}
\hline $\begin{array}{l}\text { «y acomete al dios marrano»; } \\
\text { v. } 187 .\end{array}$ & $\begin{array}{l}\text { «acomete al dios marrano»; } \\
\text { v. } 187 .\end{array}$ & $\begin{array}{l}\text { «acomete al dios marrano»; } \\
\text { v. } 187 .\end{array}$ & $\begin{array}{l}\text { «acomete al dios marrano»; } \\
\text { v. } 187 .\end{array}$ \\
\hline $\begin{array}{l}\text { «satisfecho, echando pier- } \\
\text { nas»; v. } 210 .\end{array}$ & $\begin{array}{l}\text { «satisfecho, haciendo } \\
\text { piernas». }\end{array}$ & $\begin{array}{l}\text { «satisfecho, haciendo pier- } \\
\text { nas». }\end{array}$ & $\begin{array}{l}\text { "satisfecho, haciendo pier- } \\
\text { nas». }\end{array}$ \\
\hline $\begin{array}{l}\text { «el que inventó las bravezas»; } \\
\text { v. } 222 .\end{array}$ & «el que inventó la braveza». & «el que inventó la braveza». & «el que inventó la braveza». \\
\hline
\end{tabular}

Tras considerar que $O 1$ nació a la zaga del texto de Castillo Solórzano y que las modificaciones afectan a pasajes fácilmente intercambiables ${ }^{6}$, aventuramos que dichos cambios obedecen a deslices en los talleres del impresor Diego Flamenco.

\section{BIBLIOGRAFÍA CITADA}

Alarcos García, Emilio (1995). «Quevedo y la parodia idiomática». Archivum, V, 1, pp. 3-38.

Álvarez Amo, Javier, y CANo Turrión, Elena (2015). «El poeta se distancia: retóricas prologales en el Bajo Barroco». Criticón, 125, pp. 121-132.

Arellano Ayuso, Ignacio (2003). «Algunas precisiones de terminología y conceptos teóricos». En Francisco de Quevedo, Poesía satírico-burlesca. Edición, prólogo y notas de Ignacio Arellano Ayuso. Madrid: Iberoamericana, pp. 20-36.

BARrios Leví, Miguel de (1996). Las fábulas mitológicas: Flor de Apolo. Edición, prólogo y notas de Francisco J. Sedeño Rodríguez. Málaga: Universidad de Málaga.

Bermejo JimÉnez, Concepción (1989). Obra lírica de Diego Hurtado de Mendoza. Edición y estudio literario [tesis doctoral]. Murcia: Universidad de Murcia. $<$ http://www. tdx.cat/handle/10803/10961> [Consultada: 3-02-2017].

Bonilla Cerezo, Rafael (2006). Lacayo de risa ajena. El gongorismo en la "Fábula de Polifemo" de Alonso de Castillo Solórzano. Córdoba: Diputación de Córdoba.

(2009). «Góngora y Castillo Solórzano en la Fábula de Polifemo de Francisco Bernardo de Quirós», Il confronto letterario, 51, pp. 37-75.

Butzo, Catalina (1990). «El sacristán fariseo. Edición de un entremés inédito y apuntes sobre la figura del fariseo», Criticón, 50, pp. 94-112.

Bustos, Eugenio (1986). «Cultismos en el léxico de Garcilaso de la Vega». En Víctor García de la Concha (coord.), Academia Literaria Renacentista, IV: Garcilaso. Salamanca: Universidad de Salamanca, pp. 127-163.

CAldera, Ermanno (1967). «En torno a las tres primeras estrofas del Polifemo de Góngora». En Jaime Sánchez Romeralo y Norbert Poulussen (eds.), Actas del Segundo Congreso Internacional de Hispanistas. Nimega: Instituto Español de la Universidad de Nimega, pp. 227-233.

6 Se trata de los fragmentos referentes a la hipotiposis y a la topografía, cuyo trueque no afecta a la lógica narrativa. 
Calderón de la Barca, Pedro (1983). «Las visiones de la muerte», Entremeses, jácaras y mojigangas. Edición, prólogo y notas de Evangelina Rodríguez y Antonio Tordera. Madrid: Castalia.

Castillo Solórzano, Alonso (2003). Donaires del Parnaso. Edición, prólogo y notas de Luciano López Gutiérrez [tesis doctoral]. Madrid: Universidad de Madrid. $<$ http:// eprints.ucm.es/4649/> [Consultada: 20-01-2017].

Cossío, José María (1998a). Fábulas mitológicas en España, vol. 1. Madrid: Istmo. (1998b). Fábulas mitológicas en España, vol. 2. Madrid: Istmo.

CurTius, Ernest Robert (1976). Literatura europea y Edad Media latina, vol. 2. Margit Frenk Alatorre (trad.), México-Madrid-Buenos Aires: Fondo de Cultura Económica.

GARCÉS y Gralla, Gabriel (2015). Venus y Adonis. Fábula trágica. Córdoba: Universidad de Córdoba-PHEBO. < http://www.uco.es/investigacion/proyectos/phebo/sites/ default/files/venus y adonis. edicion.pdf $>$ [Consultada: 20-1-2017].

García Gavilán, Inmaculada (2002). La poesía amorosa en "El coro de las musas» de Miguel de Barrios. Córdoba: Universidad de Córdoba.

Giongi, Giulia (2014). «Alonso de Castillo Solórzano reescritor de sí mismo: algunas notas sobre los Escarmientos de amor moralizados y el Lisardo enamorado». Edad de Oro, 33, pp. 257-270.

Giral ViU, Carmen (2002). «La fábula mitológica en Juan de Moncayo». Alazet, 14, pp. 267-271.

Góngora y ARGOTE, Luis (2000). Obras completas, vol. 1. Edición, prólogo y notas de Antonio Carreira. Madrid: Fundación José Antonio de Castro.

Jauralde Pou, Pablo (1979). «Alonso de Castillo Solórzano. Donaires del Parnaso y la Fábula de Polifemo». Revista de Archivos, Bibliotecas y Museos, 82, pp. 727-766.

LóPEz BuEno, Begoña (2005). «Derivaciones áureas del locus amoenus: de la poesía a la novela». Edad de Oro, 24, pp. 391-406.

LujÁN ATIENZA, Ángel Luis (2006). «Estrategias discursivas del genus turpe en la poesía de Góngora». En Joaquín Roses (coord.), Góngora hoy VIII. Góngora y lo prohibido: erotismo y escatología. Córdoba: Diputación de Córdoba, pp. 39-57.

Montero Reguera, José (1998). «Mitos clásicos y costumbrismo literario en la poesía de Alonso de Castillo Solórzano». Edad de Oro, 17, pp. 107-118.

Oltra, José Miguel (1985). «La miscelánea en Deleitar aprovechando». Criticón, 30, pp. 127-150.

Ovidio Nasón, Publio (1998). Metamorfosis. Antonio Ramírez de Verfer y Fernando Navarro Antolín (trads.), Madrid: Alianza.

Padilla, Pedro de (2008). Thesoro de varias poesías. Edición, prólogo y notas de José J. Labrador Herraiz y Ralph A. DiFranco. Guadalajara: Moalde.

Perutelli, Alessandro (2000). La poesía epica latina. Dalle origine all'età dei Flavi. Roma: Carocci Editore.

Ponce CÁRdenas, Jesús (2001). Góngora y la poesía del siglo XVII. Madrid: Laberinto. (2009). «Acis y Galatea: pequeñas notas de tradición clásica». En Cinco ensayos polifémicos. Málaga: Thema, pp. 101-157.

Pozzi, Giovanni (1976). «Gida alla letura». En Giambattista Marino, L’Adone, vol.1. Milán: Mondadori, pp. 9-140. 
Roses Lozano, Joaquín (1998). «La Fábula de Adonis, Hipómenes y Atalanta de Diego Hurtado de Mendoza: grados de la imitación renacentista». En Maurilio Pérez González (coord.), Congreso Internacional sobre Humanismo y Renacimiento, vol. 2. León: Universidad de León, pp. 123-150.

Soto de Rojas, Pedro (1981). Paraíso cerrado para muchos, jardines abiertos para pocos. Los fragmentos de Adonis. Edición, prólogo y notas de Aurora Egido. Madrid: Cátedra.

Tenorio, Martha Lilia (2010) (ed.). Poesía novohispana. Antología I. México: Colegio de México, Centro de Estudios Lingüísticos y Literarios-Fundación para las Letras Mexicanas.

Recibido: $15 / 7 / 2016$

Aceptado: 3/11/2016

El collar de Adonis: Castillo Solórzano, Diego de Frías y Miguel de Barrios EN LA ESTELA DE OVIDIO

RESUMEN: Este artículo aborda la primera versión burlesca del mito de Venus y Adonis, la Fábula de Adonis de Alonso de Castillo Solórzano, hipotexto de otros dos poemas del siglo XVII, las homónimas de Diego de Frías y Miguel de Barrios. Las relaciones entre estos poemas notables y se sustentan sobre la base de la imitación. No obstante, cada autor imprime a sus versos su carácter personal, aún poco valorado por la crítica.

PAlabras ClaVE: Venus y Adonis, imitación, fábulas burlescas, Castillo Solórzano, Diego de Frías, Miguel de Barrios.

\section{The Adonis 'Necklace: Castillo Solórzano, Diego de Frías and Miguel de Barrios IN THE WAKE OF OVIDY}

ABSTRACT: This article focuses upon the first burlesque version of the myth of Venus and Adonis, the Fábula de Adonis by Alonso de Castillo Solórzano, which is the hypotext of two poems of the XVII century written by Diego de Frias and Miguel de Barrios. The relations between these poems are very remarkable and they are based on imitation. Nevertheless, each author has his own style, hardly ever studied by the critics.

Keywords: Venus and Adonis, imitation, burlesque fables, Castillo Solórzano, Diego de Frías, Miguel de Barrios. 


\section{EDAD DE ORO}

Revista de Filología Hispánica XXXVI

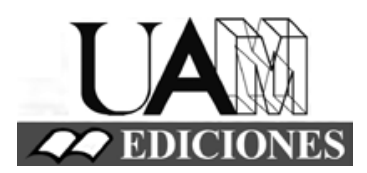




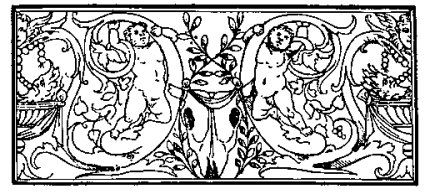

\section{Edad de Oro. Revista de Filología Hispánica}

ISSN: 0212-0429

Dirección:

Teodosio Fernández

Secretaría y edición:

José Ramón Trujillo

Consejo de redacción:

Manuel Piqueras

Blanca Santos

Admisión de originales:

María Jesús Zamora

Edad de Oro

Departamento de Filología Española

Universidad Autónoma de Madrid

28049 Madrid (España)

Tfno.: +0034914974090

correo: mariajesus.zamora@uam.es

Distribución, suscripción y venta:

Servicio de Publicaciones de la UAM

Universidad Autónoma de Madrid

28049 Madrid (España)

Intercambio de publicaciones:

Biblioteca de la Facultad de Filosofía y

Letras (UAM)

Universidad Autónoma de Madrid

28049 Madrid (España)
Comité científico internacional:

Carlos Alvar (Univ. de Ginebra)

Ignacio Arellano (Univ. de Navarra)

Javier Blasco (Univ. de Valladolid)

Alberto Blecua (UAB)

Jean Canavaggio (Univ. de París X)

Laura Dolfi (Univ. de Turín)

Aurora Egido (Univ. de Zaragoza)

Víctor García de la Concha (RAE)

Luciano García Lorenzo (CSIC)

Joaquín González Cuenca (Univ. de

Castilla-La Mancha)

Agustín de La Granja (Univ. de Granada)

Begoña López Bueno (Univ. de Sevilla)

Michel Moner (Univ. de Toulouse III)

Joan Oleza (Univ. de Valencia)

Alfonso Rey (Univ. de Santiago)

Lina Rodríguez Cacho (Univ. de Salamanca)

Leonardo Romero Tobar (Univ. de Zaragoza)

Aldo Ruffinatto (Univ. de Turín)

Lía Schwartz (City University of New York)

Han colaborado en este volumen:

Departamento de Filología Española (UAM)

Facultad de Filosofía y Letras (UAM)

Edad de Oro se recoge, entre otras, en las siguientes bases de datos: SCOPUS, MLA Database, HLAS, Latindex, PIO-Periodical Content Index, ISOC, Dialnet, MIAR, ERIH Plus, DICE, Sumaris CBUC, Ulrich's. Se encuentra evaluada en CIRC: A; MIAR difusión ICDS live 2016: 10.0; INRECH; SCImago Journal \& Country Rank: H Index 3, SJR SCImago Journal \& Country Rank 0,1, Q4; RESH índice de impacto: 0.041; ERIH: A INT1; Carhus Plus+2014: C. 